\title{
The rissaga of 15 June 2006 in Ciutadella (Menorca), a meteorological tsunami
}

\author{
A. Jansa ${ }^{1}$, S. Monserrat ${ }^{2}$, and D. Gomis ${ }^{2}$ \\ ${ }^{1}$ Instituto Nacional de Meteorologia, Palma de Mallorca, Spain \\ ${ }^{2}$ IMEDEA (University of the Balearic Islands - CSIC), Mallorca, Spain
}

Received: 6 March 2007 - Revised: 29 April 2007 - Accepted: 16 May 2007 - Published: 26 June 2007

\begin{abstract}
An extraordinary "rissaga" event (the local name for high-amplitude sea level oscillations) with 4-5 m of amplitude occurred on 15 June 2006 at Ciutadella (Menorca, Spain). In this paper we describe the rissaga event and propose that the meteorological mechanism responsible for it was an unusual pressure jump, associated with a convective squall line.
\end{abstract}

\section{Introduction}

"Rissaga" is the local name for sea level oscillations characterized by their large amplitude (1 $\mathrm{m}$, in usual cases) and short period (around $10 \mathrm{~min}$ ) observed in Ciutadella harbour. Simultaneously to the occurrence of rissaga events in Ciutadella, sea level oscillations are also observed in other inlets of the Balearic Islands (Spain; see geographical details in Fig. 1) and even in the Mediterranean shores of the Iberian Peninsula, but with smaller amplitudes. Rissaga events typically occur several times a year (mainly in summer) and they usually produce only minor problems to the harbour functionality.

A rissaga event is very similar to a tsunami: there are one or two large sea level oscillations, but they are accompanied, before and after, by smaller amplitude oscillations. The total duration of a event can range between a few hours and a couple of days. The event of 15 June 2006 was not recorded, since no tide gauge was deployed at Ciutadella at the time. However, previous events have been recorded and described in previous works (see Fig. 2 as an example). The difference between a rissaga and a tsunami is basically the ultimate origin of the oscillations: tsunamis are generated by a submarine earthquake, while rissagas have a meteorological origin (Monserrat et al., 2006).

Correspondence to: A. Jansa

(jansa@inm.es)
In order to understand the generation mechanism of a rissaga, the concept of "seiche" must be first introduced. Every port, bay or inlet has a natural oscillation mode or seiche with a period determined by the physical characteristics of the water body. The natural seiche of Ciutadella inlet has a period of $10.5 \mathrm{~min}$ (according to analytical models and from direct measurements). Natural seiches usually have very small amplitude (of the order of a few cm at most) and can hardly be visually detected. They appear when the body water oscillates around the equilibrium after some small perturbation. However, sometimes they can reach large amplitudes when they are amplified due to resonance with an external exciter. It is in these cases that the resulting sea level oscillations are referred as a "rissaga" event.

The rissaga is thought to be ultimately forced by some kind of meteorological disturbance resulting in rapid sealevel pressure oscillations. These oscillations can be due to atmospheric gravity waves (Ramis and Jansa, 1983; Monserrat et al., 1991a, b) and/or to convective pressure jumps (Jansa, 1986). In any case, the atmospheric pressure oscillations generate long surface waves in the ocean which in turn produce an amplified "seiche" whitin the inlet (Tintoré et al., 1988; Gomis et al., 1993; Garcies et al., 1996).

The general synoptic pattern associated with a rissaga is characterised by (1) low level Mediterranean air, with a weak surface depression, (2) warmer African air blowing above, around $850 \mathrm{hPa}$, with an inversion layer separating (1) and (2); and (3) a poorly stable or even a conditionally unstable layer between the African air and colder air in the upper levels, with a marked vertical wind shear across this layer (usually with strong south-westerly wind blowing at upper levels). The described pattern was reported in detail by Ramis and Jansa (1983). Gravity waves (and/or convection) appear in the layer (3) and the vertical oscillations are transmitted to the inversion layer, resulting in pressure oscillations at surface (Ramis and Jansa, 1983; Monserrat et al., 1991a, b). These surface atmospheric pressure oscillations induce small

Published by Copernicus Publications on behalf of the European Geosciences Union. 


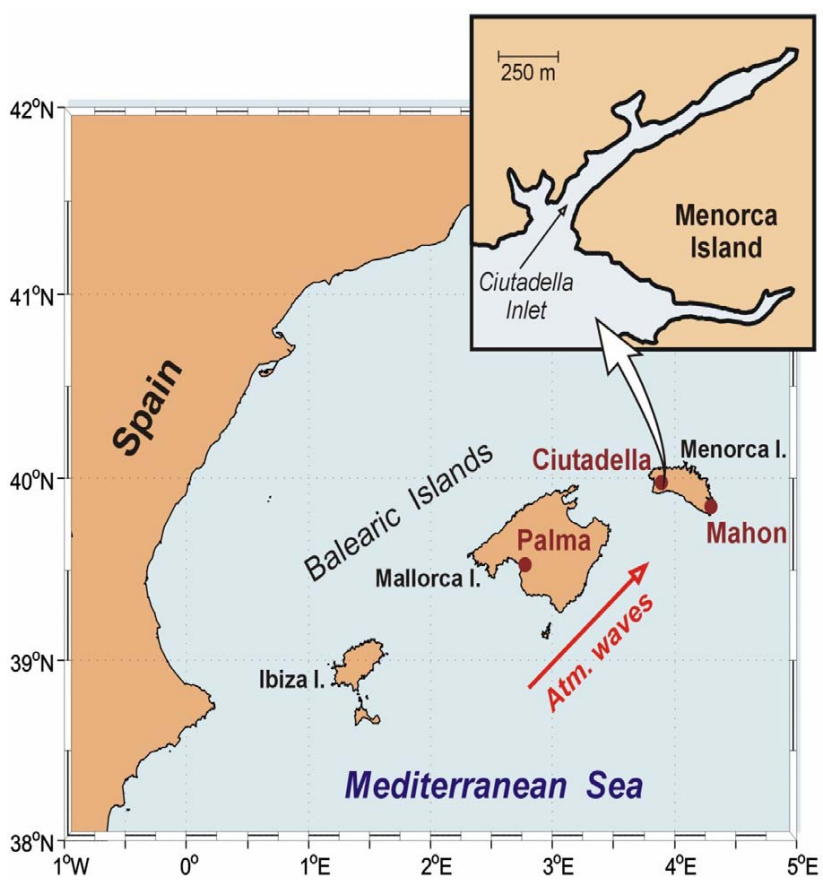

Fig. 1. Geographical details (see text).

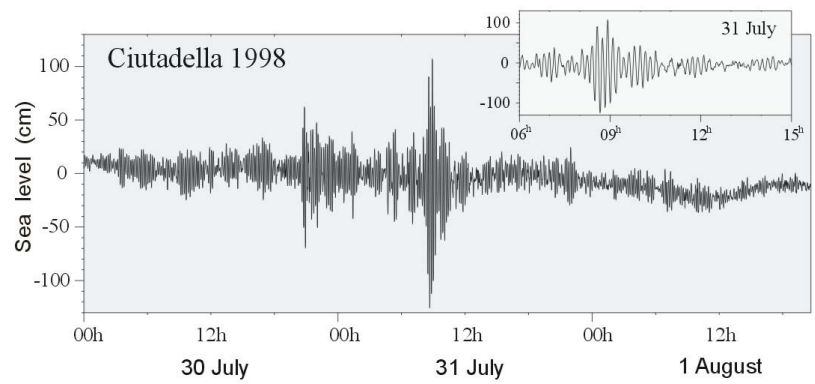

Fig. 2. Mareographic register of rissagas: around $21 \mathrm{~h}$, on 30 July 1998 , and around $09 \mathrm{~h}$, on the $31 \mathrm{st}$; the second is the most important, around $2 \mathrm{~m}$ of total amplitude (obtained by experimental instruments of the University of the Balearic Islands).

amplitude long marine waves that are amplified by several mechanisms, the last one being the resonance with the seiche of the port (Tintoré at al., 1988; Alonso et al., 1989; Gomis et al., 1989).

Note that the general weather situation that favours the rissaga is quite similar to the kind of situation that produces heavy rain and severe weather in the Western Mediterranean in general and in the Balearics in particular. The main difference is the thermal inversion: warmer African air flowing above colder Mediterranean air. The thermal inversion prevents the mixing of the low layer humid Mediterranean air with the African air and then the convection, if occurs, is mainly an upper layer phenomenon, with no large water content. Since most of the rissaga events occur between late
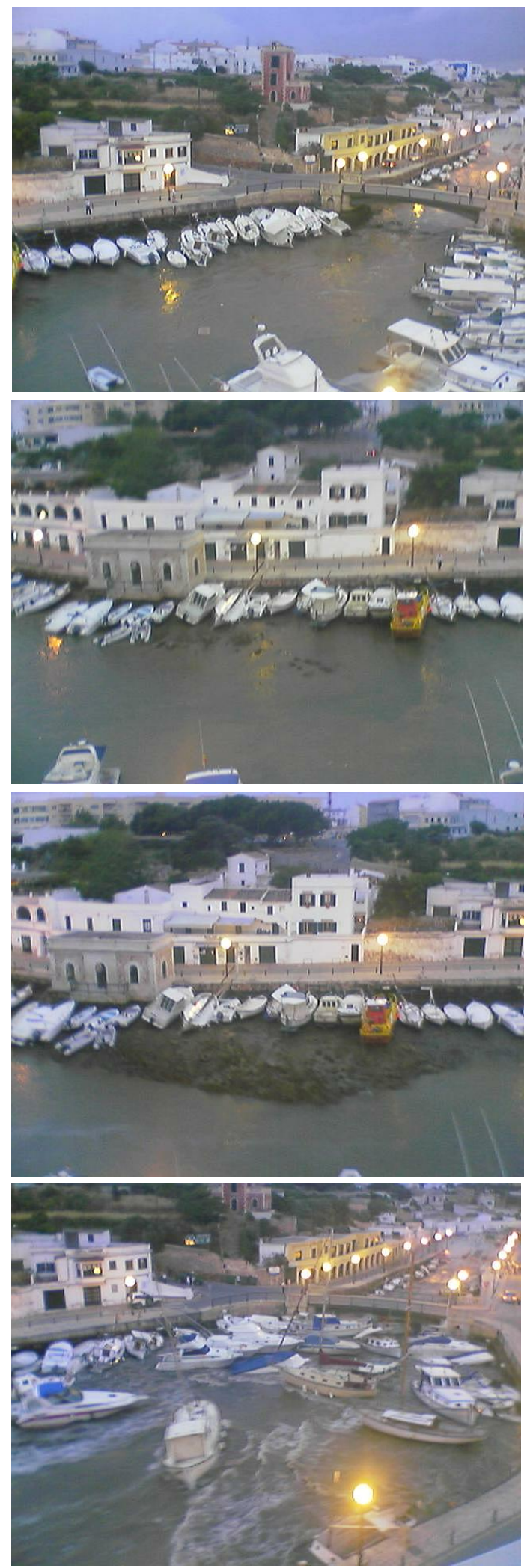

Fig. 3. Four moments of the rissaga of 15 June 2006 (pictures from Internet; unknown author). 


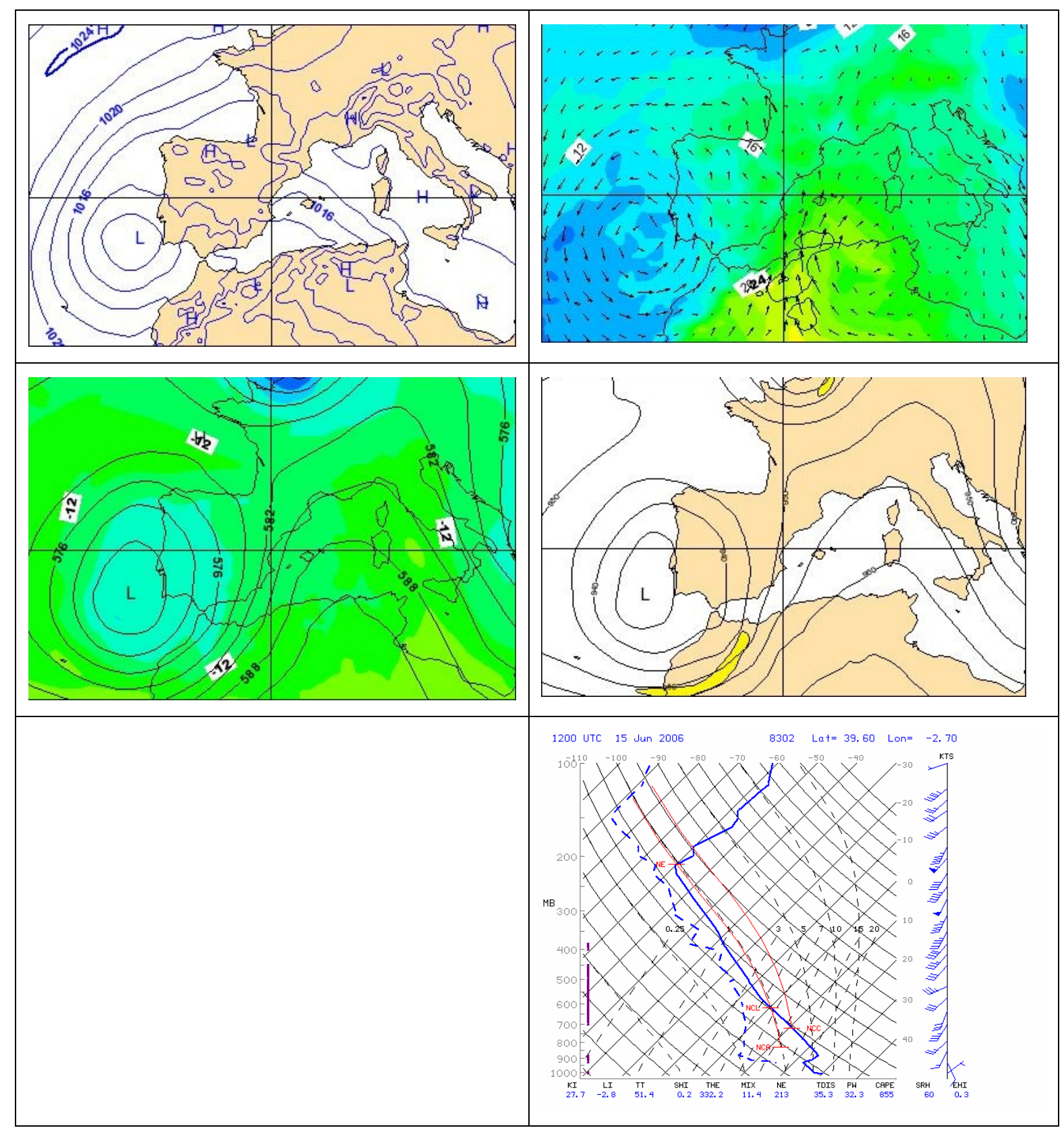

Fig. 4. General atmospheric situation on 15 June 2006, at 12:00 UTC. From left to right and from up to down, MSLP isobars, $850 \mathrm{hPa}$ wind and temperature, $500 \mathrm{hPa}$ geopotential and temperature, and $300 \mathrm{hPa}$ geopotential and wind speed (ECMWF analyses) and vertical profile (Palma de Mallorca radiosounding).

spring and early summer, when the Mediterranean Sea is still relatively cold and the Mediterranean air is much colder than the African air. Conversely, heavy rain occur mainly in autumn, when the Mediterranean Sea and so the Mediterranean air are much warmer.

\section{The event of 15 June 2006}

On 15 June 2006 an extraordinary rissaga event was reported, with $4-5 \mathrm{~m}$ of amplitude and catastrophic consequences: around 100 boats were damaged and 35 of them were sunk. An impressive pressure rise, accompanied by strong wind, caused by a squall line system, is the probable origin of that extraordinary event. An analogous convective disturbance 


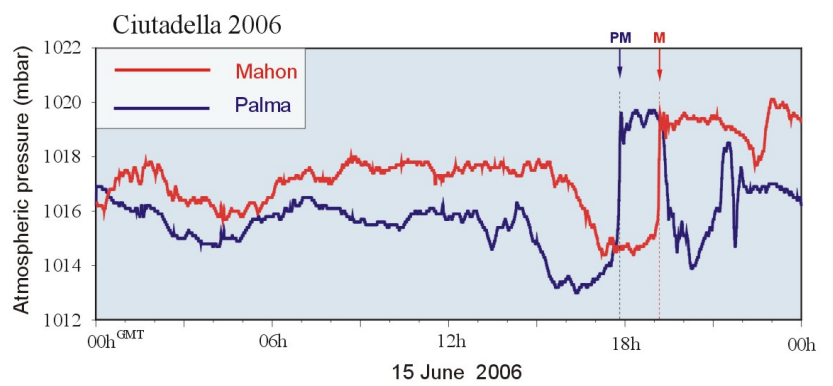

Fig. 5. Atmospheric pressure records at the observatories of Palma and Mahon airports (Instituto Nacional de Meteorologia).

was identified in another catastrophic rissaga occurred on the 21 June 1984 (Jansa, 1986). Figure 3 shows some moments of the 15 June event: the port was first drained and after refilled. The event started around 19:00 UTC and noticeable amplitude oscillations lasted for about $1 \mathrm{~h}$.

Figure 4 shows the general atmospheric situation on 15 June 2006 at 12:00 UTC, at different levels. Note that this situation matches the typical rissaga situation described in the previous section. At surface there is a weak surface depression between the Balearic Islandas and the African coast. At $850 \mathrm{hPa}$ the entrance of warm African air from the south is well apparent. At upper levels (500 and $300 \mathrm{hPa}$ ) a cold cut-off low is located to the west of the Iberian Peninsula, producing quite strong south-westerly winds above the Western Mediterranean and above the Balearics in particular. The three-layer structure described in the introduction is also well apparent in the vertical profile of the Palma de Mallorca radiosounding (Fig. 4, below). The layer between 850 and $500 \mathrm{hPa}$ presents conditional instability and vertical wind shear, which favours gravity waves formation and even convection. In fact, atmospheric gravity waves (see Fig. 5) and moderate sea level oscillations (around $1 \mathrm{~m}$ of amplitude) were observed during the day, previously to the occurrence of the largest amplitudes.

Late in the afternoon a convective nucleus formed to the south of the Balearic Islands, moving to the NE. This convective nucleus can be described as a severe system, but very inefficient with regard to rainfall reaching surface. In fact the rainfall collected in the observatories of the Balearics was only $2-3 \mathrm{~mm}$ at most. Associated with this convective nucleus, a squall line was also observed. The squall line, characterised by sudden and strong (uo to $70-80 \mathrm{~km} / \mathrm{h}$ ) wind gusts, lasting only several minutes, was accompanied by an impressively abrupt jump in the atmospheric pressure. Figure 5 shows the high resolution pressure record obtained at the observatories of Palma and Mahon airports (Instituto Nacional de Meteorologia). The pressure jump probably arrived at Ciutadella around 19:00 UTC, when the rissaga event occurred. Our hypothesis is that the pressure jump formed a singular jump in sea level followed by a tail of long waves before it arrived in Ciutadella.

\section{Conclusions: forecasting the rissaga}

The Meteorological Centre of the Spanish Instituto Nacional de Meteorologia at the Balearics is forecasting rissaga events since 1984 (Jansa, 1990). Typically, a "rissaga warning" is given when the weather situation described in the introduction is anticipated from current weather forecasts. Hence, warnings can be issued between two days and a few hours in advance. The 15 June 2006 a "rissaga warning" has been issued since the day before. However, anticipating the actual sea level amplitude and then the catastrophic characteristics of a particular event is a much harder task, as it should be based on the watching of strong convection, with singular pressure jumps, within the general weather situation favourable to the rissaga and a better knowledge of the energy transfer process between the atmosphere and the ocean.

Acknowledgements. To the unknown author of the pictures of Fig. 2.

Edited by: P. Alpert, H. Saaroni, and E. Heifetz

Reviewed by: two anonymous referees

\section{References}

Garcies, M. D., Gomis, D., and Monserrat, S.: Pressure-forced seiches of large amplitude in inlets of the Balearic Islands. Part II: Observational study, J. Geophys. Res., 101, 6453-6467, 1996.

Gomis, D., Monserrat, S., and Tintoré, J.: Pressure-forced seiches of large amplitude in inlets of the Balearic Islands, J. Geophys. Res., 98, 14 437-14 445, 1993.

Jansa, A.: Respuesta marina a perturbaciones mesometeorológicas: la rissaga de 21 de Junio de 1984 en Ciutadella (Menorca), Revista de Meteorología (AME), junio, 5-29, 1986

Jansa, A.: Servei experimenmtal de predicció de rissagues, in Les Rissagues de Ciutadella i altres oscillacions de nivell de la mar de gran amplitud a la Mediterránea (1987), 85-91, ed. IME, 1990.

Monserrat, S., Ramis, C., and Thorpe, A. J.: Large amplitude pressure oscillations in the Western Mediterranean, Geophys. Res. Lett., 18, 183-186, 1991a.

Monserrat, S., Ibbetson, A., and Thorpe, A. J.: Atmospheric gravity waves and the "rissaga" phenomenon, Q. J. Roy. Meteor. Soc., 117, 553-570, 1991b.

Monserrat, S., Vilibic, I., and Rabinovich, A. B.: Meteotsunamis: atmospherically induced destructive ocean waves in the tsunami frequency band, Nat. Hazards Earth Syst. Sci., 6, 1035-1051, 2006 , http://www.nat-hazards-earth-syst-sci.net/6/1035/2006/.

Ramis, C. and Jansa, A.: Condiciones metreorológicas simultáneas a la aparición de oscilaciones del nivel del mar de amplitude extraordinaria en el Mediterráneo occidental, Revista de Geofísica, 39, 35-42, 1983.

Tintoré, J., Gomis, D., Alonso, S., and Wang, D. P.: A theoretical study of large sea level oscillations in the western Mediterranean, J. Geophys. Res., 93, 10 797-10 803, 1988. 